\title{
EGU21-2150
}

https://doi.org/10.5194/egusphere-egu21-2150

EGU General Assembly 2021

(c) Author(s) 2022. This work is distributed under

the Creative Commons Attribution 4.0 License.

\section{Impacts of assimilating Arctic surface sea salinities from SMOS in a coupled ocean and sea ice reanalysis}

\author{
Jiping Xie ${ }^{1}$, Roshin P. Raj ${ }^{1}$, Laurent Bertino ${ }^{1}$, Justino Martínez ${ }^{2}$, Carolina Gabarró ${ }^{2}$, and Rafael \\ Catany3 $^{3}$ \\ ${ }^{1}$ Nansen Environmental and Remote Sensing Center, Bergen, Norway (jiping.xie@nersc.no) \\ ${ }^{2}$ Barcelona Expert Center, Barcelona, Spain \\ ${ }^{3}$ ARGANS, Plymouth, UK
}

In the Arctic, the sea surface salinity (SSS) has a key role in processes related to mixing, sea ice melt and freeze. However, due to insufficient salinity observations, uncertainties in present Arctic ocean forecasts and reanalysis are still large. Thanks to the European Space Agency's (ESA) Soil Moisture and Ocean Salinity (SMOS) mission, two successive versions of regional gridded SSS products for the Arctic Ocean have been developed by the Barcelona Expert Centre (BEC). These two SSS products (V2 and V3) are available from the BEC (http://bec.icm.csic.es/) and the Arctic+Salinity project funded by the ESA (https://arcticsalinity.argans.co.uk).

In this study, we show the impacts of assimilating the SMOS SSS in a coupled ocean and sea ice forecasting system.

TOPAZ4, the Arctic component of the Copernicus Marine Environment Monitoring Services (CMEMS), is a coupled ice-ocean data assimilative system, using the Ensemble Kalman Filter (EnKF) to assimilate jointly all available ocean and sea ice observations over the whole Arctic. Via the CMEMS portal, TOPAZ4 provides the products of both reanalysis and operational forecasts. Two parallel runs of TOPAZ4 are integrated from July to December in 2016, during which either the V2 or V3 SSS data product is assimilated in addition to other available data sources (altimeter data, SST, sea ice concentration, sea ice drift, T/S profiles, sea ice thickness). Independent in situ salinity profiles are used for validation of the model runs in three regions: 1) in the Beaufort Sea; 2) around Greenland; 3 ) in the Nordic Seas. Compared to the runs without SSS assimilation, the results show the reduction of a severe saline bias in the Beaufort Sea: $15.9 \%$ (V2) and $28.6 \%$ (V3), also the Root Mean Squared differences (RMSD) decreased by $10.8 \%$ (V2) and $16.2 \%$ (V3). Around Greenland, the SSS bias is decreased by $17.3 \%$ and the RMSD by $8.2 \%$ (V3 only). There are neither degradations or improvements for V2 both around Greenland and in the Nordic Seas. These basic statistics suggest the benefits of assimilating SMOS data on the TOPAZ4 outputs and the advantages from the V3 SSS product especially compared to the V2 product.

Keywords: Arctic Ocean; Sea Surface Salinity; TOPAZ4; In situ; RMSD; 